\title{
COMPARATIVE EVALUATION OF EFFICACY OF METERED DOSE INHALERS (FLUTICASONE AND SALMETEROL) WITH SPACER AND WITHOUT SPACER IN CHILDHOOD BRONCHIAL ASTHMA
}

\author{
Suddapalli Sivaram Prasad ${ }^{1}$ \\ ${ }^{1}$ Associate Professor, Department of Paediatrics, Katuri Medical College and Hospital, Guntur.
}

\section{ABSTRACT}

\section{AIM}

To compare efficacy of MDI (Metered dose inhaler) with spacer and without spacer using combination drugs of fluticasone and salmeterol in childhood bronchial asthma.

\section{MATERIALS AND METHODS}

A prospective study was planned with 56 patients of both sexes in the age group of 5-12 years, who reported to Asthma Clinic and fulfilled inclusion and exclusion criteria after parental consent. All patients included in the trail were initially entered into runin period of 2 weeks, during which a record was maintained of their clinical parameters and allowed to take their prescribed medication. At the end of run-in period the baseline symptoms and signs of asthma, PFT, amount of rescue medication and nocturnal awakening due to asthma symptoms were recorded. After run-in period, based on computer generated random number tables, patients were randomized to receive MDI (Fluticasone 125 micrograms and salmeterol 25 micrograms) either with spacer or without spacer. Statistical analysis was performed to compare both groups.

\section{CONCLUSION}

The present study demonstrated that there is no significant difference between with spacer group and without spacer group in clinical and PFT improvements in childhood bronchial asthma.

\section{KEYWORDS}

Asthma, Children, Pulmonary Function Test (PFT), Fluticasone, Salmeterol, Spacer, MDI.

HOW TO CITE THIS ARTICLE: Suddapalli Sivaram Prasad. "Comparative Evaluation of Efficacy of Metered Dose Inhalers (Fluticasone and Salmeterol) with Spacer and Without Spacer in Childhood Bronchial Asthma." Journal of Evolution of Medical and Dental Sciences 2015; Vol. 4, Issue 98, December 07; Page: 16334-16336, DOI: 10.14260/jemds/2015/2412

\section{INTRODUCTION}

Bronchial asthma is common disease among children. Various devices are used to deliver medication to the site of disease process. MDI is the most commonly used and cheapest device, which may also be used in conjunction with a spacer device. The MDI originated when in the spring of 1955, 13-year-old Susie, the daughter of the then Managing Director of Riker Laboratories, Inc., asked her father, “Daddy, why can't they put my asthma medicine in a spraycan like they do hair spray?". ${ }^{1}$ A systemic review of three trials in children and 21 trials in adults by D. Brocklebank and others demonstrated that there is no evidence to suggest clinical benefits of any other inhaler device over an MDI in corticosteroid delivery. ${ }^{2}$ The evidence from the published clinical literature demonstrates no difference in clinical effectiveness between nebulizers and alternative inhaler devices compared to standard MDI with or without a spacer device. ${ }^{2}$ The cost-effectiveness evidence favors MDIs (Or the cheapest inhaler device) as first-line treatment in all patients with stable asthma unless other specific reasons are identified.2 Patients can use MDIs as effectively as other inhaler devices as long as the correct inhalation technique is taught. ${ }^{2}$

However, MDIs are not without their own issues which include patients' difficulties with their correct, coordinated

Financial or Other, Competing Interest: None.

Submission 16-11-2015, Peer Review 17-11-2015,

Acceptance 27-11-2015, Published 05-12-2015.

Corresponding Author:

Dr. Suddapalli Sivaram Prasad,

Flat No: 4, First Floor

Amrutha Apartments,

Veterinary Colony, Road No. 5

Vijayawada-5, Andhra Pradesh, India.

E-mail: suddapalli2000@yahoo.com

DOI:10.14260/jemds/2015/2412 use; many patients including the very young, confused, intellectually impaired, or those experiencing acute severe breathlessness will be unable to inhale in anything other than tidal breaths. ${ }^{3}$ It is some of these issues that spacers are designed to overcome. Is MDI efficacy with spacer is equivalent to MDI without spacer when used for delivery of combination drugs (Fluticasone and salmeterol)? We have undertaken this study to evaluate this issue.

\section{MATERIALS AND METHODS}

This study was conducted in Asthma Clinic of the Pediatric OPD, at Katuri Medical College and Hospital, Guntur, between 2012 and 2013. A prospective study was planned with 56 patients of both sexes in the age group of 5-12 years, who reported to Asthma Clinic and fulfilled inclusion and exclusion criteria after parental consent. All patients included in the trial were initially entered into run-in period of 2 weeks, during which a record was maintained of their clinical parameters and allowed to take their prescribed medication. At the end of run-in period, the baseline symptoms and signs of asthma, PFT, amount of rescue medication and nocturnal awakening due to asthma symptoms were recorded.

After run-in period, based on computer generated random number tables, patients were randomized to receive MDI (Fluticasone 125 micrograms and salmeterol 25 micrograms) either with spacer or without spacer. Blinding could not be done because of nature of the trial. However, all precautions taken for good study. Various parameters like symptom score (e.g. cough, breathlessness), clinical score (e.g. Wheeze, use of accessory muscles) PFT (e.g. FEV1, FVC, PEFR), nocturnal awakening (e.g. number of nights in a week patient awakened due to asthma symptoms as per history), use of rescue medication (Number of salbutamol puffs patient required per week) were used to assess efficacy of device at 
monthly intervals for two months. Statistical analysis was performed between data of both groups.

\section{RESULTS}

In this study, a total of 56 children with moderate persistent asthma fulfilled inclusion and exclusion criteria and included in the study. Out of total 56 children studied, 32 subjects $(57.14 \%)$ were male and 24 subjects $(42.85 \%)$ were female. There were 34 patients $(60.71 \%)$ in the age group 5-8 years and 22 patients $(39.28 \%)$ in the age group of $9-12$ years. There are two groups, which underwent intervention in the form of MDI (Fluticasone propionate 125 micrograms and salmeterol 25 micrograms) inhalation either with spacer or without spacer. Before intervention, baseline characters of both groups were compared and analyzed. There was no statistically significant difference between two groups in relation to age, weight and height.

Before intervention, there was no statistically significant difference between two groups for baseline characters like symptom score (e.g. cough, breathlessness), clinical score (e.g. wheeze, use of accessory muscles), PFT (e.g. FEV 1 , FVC, PEFR), nocturnal awakening (number of nights in a week patient awakened due to asthma symptoms as per history) and use of rescue medication number of salbutamol puffs patients required per week). There is no statistically significant difference between with spacer group and without spacer group at first review after one month and second review after two months post intervention.

\begin{tabular}{|c|c|c|c|c|c|c|c|c|c|}
\hline \multirow{2}{*}{$\begin{array}{c}\text { Sl. } \\
\text { No. }\end{array}$} & \multirow{2}{*}{ CHARACTER } & \multicolumn{3}{|c|}{ MDI Without Spacer } & \multicolumn{2}{c|}{ MDI With Spacer } & \multirow{2}{*}{ P-value } & \multirow{2}{*}{ SIGNIFICANCE } \\
\cline { 2 - 9 } & Mean & SD & S.Err & Mean & SD & S.Err & & \\
\hline 1 & Symptom score & 1.520 & 0.943 & 0.178 & 1.179 & 0.927 & 0.175 & $>0.005$ & Not sig \\
\hline 2 & Clinical score & 0.541 & 0.967 & 0.183 & 0.321 & 0.477 & 0.090 & $>0.005$ & Not sig \\
\hline 3 & FEV1 & 88.59 & 8.970 & 1.696 & 88.31 & 9.030 & 1.707 & $>0.005$ & Not sig \\
\hline 4 & FVC & 80.33 & 8.712 & 1.647 & 79.92 & 10.68 & 2.019 & $>0.005$ & Not sig \\
\hline 5 & PEFR & 87.17 & 13.04 & 2.465 & 90.55 & 13.91 & 2.629 & $>0.005$ & Not sig \\
\hline 6 & Nocturnal awakening & 1.149 & 0.952 & 0.179 & 0.565 & 0.902 & 0.171 & $>0.005$ & Not sig \\
\hline 7 & Rescue medication & 2.520 & 2.300 & 0.434 & 1.789 & 0.242 & 0.046 & $>0.005$ & Not sig \\
\hline \multicolumn{10}{|c|}{ Table 1: Comparison of MDI Without Spacer and MDI With Spacer (1 seview) } \\
\hline
\end{tabular}

\begin{tabular}{|c|c|c|c|c|c|c|c|c|c|}
\hline \multirow{2}{*}{$\begin{array}{l}\text { SL. } \\
\text { No. }\end{array}$} & \multirow{2}{*}{ CHARACTER } & \multicolumn{3}{|c|}{ MDI Without Spacer } & \multicolumn{3}{|c|}{ MDI With Spacer } & \multirow{2}{*}{ P-value } & \multirow{2}{*}{ SIGNIFICANCE } \\
\hline & & Mean & SD & S.Err & Mean & SD & S.Err & & \\
\hline 1 & Symptom score & 0.455 & 0.657 & 0.124 & 0.202 & 0.422 & 0.080 & $>0.005$ & Not sig \\
\hline 2 & Clinical score & 0.105 & 0.423 & 0.079 & 0.095 & 0.401 & 0.075 & $>0.005$ & Not sig \\
\hline 3 & FEV1 & 90.69 & 7.091 & 1.340 & 88.60 & 8.205 & 1.551 & $>0.005$ & Not sig \\
\hline 4 & FVC & 82.68 & 9.110 & 1.722 & 79.72 & 9.804 & 1.853 & $>0.005$ & Not sig \\
\hline 5 & PEFR & 91.01 & 11.15 & 2.108 & 93.90 & 14.87 & 2.811 & $>0.005$ & Not sig \\
\hline 6 & Nocturnal awakening & 1.365 & 0.684 & 0.129 & 0.243 & 0.685 & 0.129 & $>0.005$ & Not sig \\
\hline 7 & Rescue medication & 0.613 & 1.612 & 0.305 & 0.653 & 0.620 & 0.117 & $>0.005$ & Not sig \\
\hline
\end{tabular}

\section{DISCUSSION}

In the present day scenario, bronchial asthma is a leading cause of morbidity in our society and more so in pediatric age group. ${ }^{4}$ There have been revolutionary changes in the management of bronchial asthma during past few years. Aerosol therapy has come to stay as the backbone of therapy. Acute attacks in the pediatric age group require hospital management and nebulization is primary mode of drug delivery to the lungs. ${ }^{5}$ However, recently MDI with spacer is emerging as alternative to nebulizer as per numerous studies. In this scenario, more evidence need to accumulate in favor of MDI with spacer before it becomes a universal practice in Emergency Departments. Present study focused on efficacy comparison of MDI with spacer and without spacer.

A total of 56 subjects were evaluated after random allocation to either group. Before random allocation, one month after random allocation and two months after random allocation, various disease parameters like symptom score, clinical score, PFT, nocturnal awakening due to asthma symptoms and rescue medication required recorded. Data from baseline, one month after application of medication and two months after application of medication was analyzed for both groups and compared. There was no statistically significant difference between both groups, indicating that both of them are equally effective. Hashem Rohmati and others from UK found similar results. ${ }^{6}$ In vivo studies demonstrated that reduced deposition of chemical in oropharynx and stomach and increased whole lung deposition of chemical by application of spacer. ${ }^{3}$

\section{CONCLUSION}

This study demonstrate that correct use of MDI with spacer and without spacer produce same clinical efficacy. MDI with spacer is a good substitute for MDI alone. Optimal inhalation technic of MDI with spacer is less demanding than MDI alone. However, sample size of this study was small and different types of spacers not studied. Further research is considered as essential to establish this finding and to study other associated issues.

\section{BIBLIOGRAPHY}

1. Thiel CG: From Susie's question to CFC free: an inventor's perspective on forty years of MDI development and regulation. In: RN Dalby, PR Byron, and SJ Farr, (eds). Respiratory Drug Delivery, 5th ed. Inter pharm Press, Buffalo Grove, IL; pp. 115-123, 1996.

2. Brocklebank D, Ram F, Wright J, Barry P, Cates C, Davies L, Douglas G, Muers M, Smith D, White J. Comparison of the effectiveness of inhaler devices in asthma and chronic obstructive airways disease: a systematic review of the literature: Health Technology Assessment 2001; Vol. 5: No. 26.

3. Kurt Nikander, Clare Nicholls, John Denyer, John Pritchard. The Evolution of Spacers and Valved Holding Chambers: J Aerosol Med Pulm Drug Deliv 2014 Aug; 27 Suppl 1:S4-23. 
4. Vandane Bathra, Sathi GR, Sachdeva HP. Comparative efficacy of jet nebulizer and meter dose inhaler with spacer device in the treatment of acute asthma: Ind Ped 1997;34.

5. Pederson S. Choice of Inhalation Therapy in Pediatrics: Ero Resp Rev 1994;4:15-68.
6. Hashem Rahmati, Fatemeh Ansarfard, Fariba Ghodsbin, Mohammad Ali Ghayumi, Mehrab Sayadi. The Effect of Training Inhalation Technique with or without Spacer on Maximum Expiratory Flow Rate and Inhaler Usage Skills in Asthmatic Patients: A Randomized Controlled Trial: IJCBNM October 2014; Vol 2, No 4. 